\title{
Effects of defatted dried roselle (Hibiscus sabdariffa L.) seed powder on lipid profiles of hypercholesterolemia rats.
}

\begin{abstract}
BACKGROUND: In vivo investigations were made of the effect of defatted dried roselle seed powder (DRS) on the lipid profiles of rats with induced hypercholesterolemia. The twobatch sample consisted of 23 and 20 Sprague-Dawley male rats randomly divided into four groups and fed with four different diets. The first batch of rats was fed with normal, hypercholesterol, hypercholesterol $+10 \mathrm{~g} \mathrm{~kg}-1$ (w/w) DRS and hypercholesterol $+20 \mathrm{~g} \mathrm{~kg}-1$ (w/w) DRS diets. The second batch of rats was fed with normal, hypercholesterol, hypercholesterol + $50 \mathrm{~g} \mathrm{kg-1} \mathrm{(w/w)} \mathrm{DRS} \mathrm{and} \mathrm{hypercholesterol} \mathrm{+} 150 \mathrm{~g} \mathrm{kg-1}$ (w/w) DRS diets. Treatments were given for a total of 5 weeks. RESULTS: Results indicated that the addition of $10 \mathrm{~g} \mathrm{~kg}-1$ and $20 \mathrm{~g} \mathrm{~kg}-1$ of DRS did not significantly lower the plasma total cholesterol (TC) levels. In contrast, $50 \mathrm{~g} \mathrm{kg-1}$ and $150 \mathrm{~g} \mathrm{~kg}-1$ DRS significantly lowered (P \&lt; 0.05) the TC and low density lipoprotein cholesterol (LDL-C) levels. CONCLUSION: The addition of $50 \mathrm{~g} \mathrm{~kg}-1$ and $150 \mathrm{~g} \mathrm{~kg}-1$ DRS showed potential hypocholesterolemic effects. Furthermore, these findings indicated that protein, lipid and dietary fibre were high in the seed powder.
\end{abstract}

Keyword: Hypocholesterolemic effects; Low density lipoprotein cholesterol; Roselle seeds; Total cholesterol. 